\section{Edycasáa $p_{\text {ond }}$

RESENHA

\title{
A crise na educação entre o passado e o futuro
}

\author{
José Luís Schifino Ferraroa
}

\section{Editor}

Maria Inês Côrte Vitoria

PUCRS, RS, Brasil

\section{Equipe Editorial}

Pricila Kohls dos Santos PUCRS, RS, Brasil

Marcelo Oliveira da Silva PUCRS, RS, Brasil

Carla Spagnolo

PUCRS, RS, Brasil

Rosa Maria Rigo

PUCRS, RS, Brasil

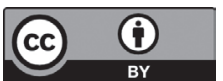

\section{RESENHA DE:}

\author{
ARENDT, Hannah. A crise na educação. [Ensaio] \\ In: ARENDT, Hannah. Entre o passado e o futuro. \\ 7. ed. São Paulo: Perspectiva, 2011. 348 p.
}

No início de seu ensaio intitulado "A crise na educação", Hannah Arendt focaliza os acontecimentos do século XX interconectados - principalmente as guerras e àquilo que decorreu delas - caracterizando, assim, tal crise como "fato político" (e até certo ponto generalizado) que ainda hoje persiste e se constitui como tema recorrente na imprensa (ARENDT, 2011, p. 221-222). Arendt também coloca que a vantagem da análise em uma perspectiva crítica além de nos exigir respostas às questões que estão sendo colocadas em xeque, nos permite descortinar os problemas em sua essência, que no caso da educação, segundo a autora, passa pela questão da natalidade, visto que os seres humanos "nascem para o mundo" (ARENDT, 2011, p. 222).

A ênfase em tratar tal crise com uma conotação política toma como referência a educação que passa a ser realizada nos Estados Unidos, visto que a "América" principalmente no pósguerra passou a receber um número considerável de imigrantes. A escola então, passou a cumprir um papel que em outros países fica basicamente à cargo da família - ocorre no lar - que se refere à educação da língua inglesa. Houve, então, o que Arendt denominou de "americanização" dos estudantes filhos de imigrantes (ARENDT, 2011, p. 223).

\footnotetext{
a Doutor em Educação, Professor da Faculdade de Biociências e do Programa de Pós-graduação em Educação em Ciências e Matemática da PUCRS. <jose.luis@pucrc.br>.
} 
Hannah Arendt faz uma dura crítica à relação entre educação e política stricto sensu. Cabe observar aqui que não considera a dimensão política do ato de educar, mas separa a educação de uma atividade política que é estritamente governamental, a forma de governo dos Estados. Enfatiza o papel da educação das novas gerações baseada na "superioridade do adulto" como estratégia ditatorial para alienação e submissão a determinados regimes e formas de governo. É enfática ao escrever que a educação não pode desempenhar um papel nesta política a qual se refere, pois os "adultos já estão educados" e que qualquer tipo de intervenção educativa nestes indivíduos seria uma tentativa de desvinculá-los das atividades inseridas dentro da política. Seria uma espécie de "coerção sem o uso da força" (ARENDT, 2011, p. 225).

A conclusão da autora mediante a esta questão é que para que um Estado possa instaurar uma nova ordem política mediante o uso da educação, isto é, sem utilizar força, coerção ou persuasão, deveria concentrar seus esforços em termos educacionais nas gerações mais novas. Segundo Arendt, seria uma "conclusão platônica" (e, por que não, utópica?): o "banimento de todas as pessoas mais velhas" do novo/outro Estado a ser fundado. Isto se explica, pois esta questão está implicada em uma dimensão ainda maior que diz respeito à impossibilidade da preparação das novas gerações para o que realmente é novo. A autora afirma que "pertence à própria natureza da condição humana o fato de que cada geração se transforma em um mundo antigo" (ARENDT, 2011, p. 226). Isto explica o fato de uma análise de educação centrada na transformação no sentido de renovação, que é inerente à questão da natalidade.

É exatamente isto que acaba indo de encontro com a questão da "americanização" das crianças filhas de imigrantes e que acaba por atingir também suas famílias, a partir do momento que se institui esta tentativa de abandono do "mundo antigo". A falsa crença de que na "América" se está construindo um "mundo novo". Mundo este, que na verdade, já foi construído tanto por vivos, quanto por mortos (ARENDT, 2011, p. 226). Arendt trata este ânimo do Novus Ordo Seclorum, como pathos perceptível na obra de Rousseau que toma a educação como instrumento da política e a política como forma de educação (ARENDT, 2011, p. 225).

A questão mais central do estabelecimento desta "nova ordem" está na busca pelo princípio da igualdade que não se restringe à lei, mas ao "nivelamento da distinção de classes" dos cidadãos estadunidenses, faz render uma crítica aos modos de exclusão e meritocráticos a partir dos quais está estruturado o sistema educacional europeu. Há, segundo Arendt, a formação de uma "oligarquia de talento" a partir do momento em que a meritocracia contradiz os princípios de uma democracia igualitária (ARENDT, 2011, p. 229).

A relação entre crianças e adultos, a formação dos professores e o pragmatismo em relação ao processo de ensino também são abordados como algo que contribui para a precipitação da crise em questão. Em primeiro lugar se coloca em discussão autoridade e governo. A emancipação das crianças frente à figura dos adultos acaba por sujeitá-la a autoridade mais "tirânica" de seu próprio grupo - um banimento das crianças do mundo adulto - o que teria conduzido 
a dois sentidos extremos: por um lado a um conformismo por parte das mesmas, por outro a delinquência (ARENDT, 2011, p. 231).

Ainda, o fato da Pedagogia ter se afastado das matérias específicas, do conhecimento técnico, àquilo que efetivamente deve ser ensinado. O que segundo Hannah Arendt, a teria feito se aproximar apenas de questões metodológicas o que acabou por refletir-se na formação precária do professorado que culminou no "abandono" dos estudantes "aos seus próprios recursos". A crítica vai no sentido de que cada vez mais professor foi deixando de ser autoridade em termos de conhecimento técnico (ARENDT, 2011, p. 231).

E mais: o pragmatismo como carro chefe de uma concepção de educação pautada única e exclusivamente em habilidades, no saber fazer, que só se pode conhecer e compreender aquilo que "nós mesmos fizemos". Como a autora escreve, a ideia seria "inculcar habilidades" de um "conhecimento petrificado" e não de mostrar como um conhecimento pode ser produzido (ARENDT, 2011, p. 232). Percebe-se aqui uma crítica ao currículo, a um "currículo padrão" preenchido por pré-requisitos a serem alcançados como metas.

A autora afirma que estes três pressupostos carregam em si um caráter destrutivo e que foi a partir de sua verificação se intentou nos E.E.U.U. reformar totalmente o sistema educativo, seja na modificação do currículo as quais as próprias crianças estão submetidas e o currículo que tem pautado a formação dos próprios professores para que não "negligenciem" as próprias crianças (ARENDT, 2011, p. 233-234). Feita esta observação, a intenção do texto de Hannah Arendt é o de tentar revelar os aspectos do mundo moderno - e de sua crise - que se revelaram na crise da educação e o que, de fato, se pode aprender em meio a esta condição crítica (ARENDT, 2011, p. 234).

$\mathrm{Na}$ terceira parte de sua exposição sobre a crise na educação, Arendt ressalta a característica sempre inacabada da educação na medida em que sua renovação se faz necessária muito em consequência da chegada de "novos seres humanos". O nascimento de crianças que são tomadas numa concepção de devir, uma perspectiva de formação do "vir a ser". A figura da criança frente ao educador, segundo a autora, é de "objeto" da própria educação: um ser humano novo, em um mundo que já existia e continuará a existir depois dele, inserido em um processo de formação (ARENDT, 2011, p. 234). Neste sentido surge a importância da figura dos pais, da família. A responsabilidade que assumem como via de mão dupla:

Eles assumem na educação a responsabilidade, ao mesmo tempo, pela vida e desenvolvimento da criança e pela continuidade do mundo [...] A responsabilidade pelo desenvolvimento da criança volta-se em certo sentido contra o mundo [...] a criança requer cuidado e proteção especiais para que nada de destrutivo lhe aconteça de parte do mundo. Porém também o mundo necessita de proteção, para que não seja derrubado e destruído pelo assédio do novo que irrompe sobre ele a cada geração. (ARENDT, 2011, p. 235)

Educação Por Escrito, Porto Alegre, v. 6, n. 1, p. 185-190, jan.-jun. 2015 
As paredes da casa, os limites do lar, então surgem como escudo para proteção da criança. A vida em si, para se desenvolver necessita de condições mínimas de segurança para o seu desenvolvimento. Se por um lado a educação moderna pretende construir "um mundo de crianças", por outro, retira condições necessárias ao desenvolvimento e crescimento da própria vida. O que se percebe é um choque entre a realidade de dois mundos: o público e o privado. $\mathrm{O}$ século XX emancipou a vida e as "atividades envolvidas em sua preservação e enriquecimento do ocultamento da privatividade expondo-a à luz do público". Este é o sentido da emancipação, segundo Hannah Arendt: fazer vir a público a função social de categorias implicadas no contexto social, como por exemplo, os trabalhadores, as mulheres etc. (ARENDT, 2011, p. 237). Mesmo assim, a distinção entre ambas as realidades se faz importante para o desenvolvimento da criança, para que durante este processo não haja nenhum tipo de distúrbio ou desequilíbrio.

A escola para a criança surge como barreira que separa a vida privada do mundo. A escola não é o mundo (embora o represente em certa medida, em certo sentido), mas se interpõe entre ele e o seu lar. É uma organização maior, o Estado, que pede a criança na escola, o "comparecimento ao mundo público". E assim como os pais - a família tiveram a missão de exercer um cuidado em termos vitais em um período inicial, agora é a figura do educador que surge fazendo com que este jovem passe a ser introduzindo no mundo aos poucos e mais: é importante que ele seja chamado a assumir a responsabilidade sobre este próprio mundo (ARENDT, 2011, p. 239).

A qualificação do professor consiste em conhecer o mundo e ser capaz de instruir o mundo acerca deste, porém sua autoridade se assenta na responsabilidade que ele assume por este mundo. Face à criança, é como se ele fosse um representante de todos os habitantes adultos, apontando os detalhes e dizendo à criança: - Isso é o nosso mundo. (ARENDT, 2011, p. 239)

Hannah Arendt coloca também em discussão a perda de autoridade no mundo moderno. A remoção da autoridade da vida política implicaria, segundo a autora, em uma espécie de chamamento geral, uma igual responsabilidade de todos dirigida ao cuidado com o "rumo do mundo". Isto poderia significar uma espécie de renúncia da autoridade por parte dos adultos o que pode ser encarado como a "recusa de assumir a responsabilidade pelo mundo o qual trouxeram as crianças" (ARENDT, 2011, p. 240). Resumindo: a humanidade se recusa a assumir um compromisso de cuidado com o mundo frente às novas gerações.

A prática educativa, para além da autoridade, também é abordada como elemento que faz funcionar em seu epicentro um instinto de conservação: "a criança contra o mundo, o mundo contra a criança, o novo contra o velho, o velho contra o novo" (ARENDT, 2011, p. 242). Talvez seja por isso, que por mais revolucionário seja um discurso educativo, a gênese da atividade, das práticas educativas permaneça sempre de certa forma sob um viés conservador: 
"exatamente em benefício daquilo que é novo em revolucionário em cada criança é que a educação precisa ser conservadora". Arendt ainda enfatiza que a conotação de um educar sem fim também reside no fato de que "um mundo feito por mãos mortais" corre o risco de se tornar tão "mortal" quanto seus habitantes (ARENDT, 2011, p. 243).

Para finalizar seu ensaio, a autora ainda coloca que a crise da autoridade na educação tem uma interconexão com a crise de "nossa atitude frente ao passado", ou seja, com a crise da tradição (ARENDT, 2011, p. 243). Isto acaba por tornar-se um desafio para o educador que serve como uma espécie de mediador entre presente e passado, o velho e o novo. Um passado que na tradição romana é visto como "modelo", "exemplo de conduta". Em assim sendo, o homem velho serve de modelo para os mais novos, o antepassado assim também o é em relação aos vivos (ARENDT, 2011, p. 244). "A autoridade do mestre arraigava-se firmemente na autoridade inclusiva do passado" (ARENDT, 2011, p. 245).

Segundo Hannah Arendt, o problema da educação no mundo moderno está no fato de sua natureza não poder abrir mão da autoridade e da tradição em um mundo onde sua estruturação não passa pela autoridade e tampouco é coeso pela tradição (ARENDT, 2011, p. 245). Segundo Arendt, "cumpre divorciarmos decisivamente o âmbito da educação dos demais" pelo fato de que necessita além de um conceito de autoridade específico, uma atitude frente ao passado apropriada que não conseguirá ser generalizada no mundo adulto, não possuirá "validade geral" (ARENDT, 2011, p. 246). Isto significa que a escola deve ensinar as crianças a perceberem o mundo como ele é, e não simplesmente ensiná-las a viver, pois o mundo sempre será mais velho que elas: compreender o presente pelo passado, não simplesmente devotar a aprendizagem a eventos passados descontextualizando-a do tempo presente (ARENDT, 2011, p. 246).

Para a autora, a educação deve diferenciar-se da aprendizagem porque deve ter um "final previsível". Na lógica desta modernidade este final não significa inserir o jovem no mundo como um todo, mas em um determinado segmento de mundo, na medida em que este final é tomado pela circunstância da certificação, do recebimento de um determinado diploma (ARENDT, 2011, p. 246). Por outro lado, enfatiza que "não se pode educar sem ao mesmo tempo ensinar", pois uma educação sem aprendizagem é "vazia" (ARENDT, 2011, p. 246-247). Assim, também afirma que se torna muito fácil ensinar sem educar (ARENDT, 2011, p. 247), o que dentro de uma lógica de sistemas educativos excludentes na contemporaneidade acaba se tornando corriqueiro.

Hannah Arendt encerra colocando em evidência uma questão crucial que é inerente ao processo educativo: a da constante renovação. A renovação do mundo a partir dos nascimentos nos deve fazer refletir sobre um tipo de educação que nos faça assumir o compromisso com o próprio mundo. É um momento de decisão que tange à nossa verdadeira capacidade de amar o mundo e que acaba por, de certa forma, mensurar nosso envolvimento em termos de cuidado com as coisas do próprio mundo (ARENDT, 2011, p. 247), entre elas as crianças. A educação se constitui, 
também, em um lugar onde decidimos se "amamos nossas crianças o bastante para não expulsá-las de nosso mundo e abandoná-las a seus próprios recursos" (ARENDT, 2011, p. 247). Devemos prepará-las, a partir disso, para uma tarefa renovadora o que faz emergir em sua essência o conceito de educação: tornar o outro diferente. O outro que também pode ser o mundo.

\section{Endereço para correspondência:}

José Luís Schifino Ferraro

Av. Ipiranga, 6681 - Prédio 12

90619-900 Porto Alegre, RS, Brasil

<jose.luis@pucrc.br>

Recebido em: dezembro/2014

Aceito em: março/2015 